\title{
20
}

\section{An Innovative Continuous Simulation Approach to Sizing a Sanitary Sewer System Storage \\ Facility}

\section{Li Zhang, Fang Cheng, Gregory Barden, John Schroeder and Edward Burgess}

This chapter presents an innovative approach to sizing a sanitary sewer storage facility as part of the Livingston-James sewer system infiltration and inflow (LJII) remediation project for Columbus, Ohio, with a 61 y continuous simulation period.

The LJII model was calibrated for continuous simulation to represent rainfall derived infiltration and inflow (RDII) using 2007-2008 flow monitoring data. Precipitation data for 1949 through 2009 (61 years) from the Port Columbus International Airport gauge were used to generate inflow hydrographs using the calibrated model.

The 61 y inflow hydrographs were compressed using a threshold of full capacity flow at the pipe downstream of the storage facility. Then the compressed inflow hydrographs were routed through the sewer system to size the storage facility, to achieve a design objective of a $10 \mathrm{y}$ level of service.

The results showed that using long term continuous simulation to size storage facilities can be practical, even for large complex sewer models, with special techniques to reduce the size of the inflow hydrographs routed through the conduit network.

Zhang, L., F. Cheng, G. Barden, J. Schroeder and E. Burgess. 2013. "An Innovative Continuous Simulation Approach to Size a Sanitary Sewer System Storage Facility." Journal of Water Management Modeling R246-20. doi: 10.14796/JWMM.R246-20.

(C) CHI 2013 www.chijournal.org ISSN: 2292-6062 (Formerly in Pragmatic Modeling of Urban Water Systems. ISBN: 978-0-9808853-8-5) 


\subsection{Introduction}

The continuous simulation of a collection system has become more practical and desirable in the past decades (Yeboah and Heineman, 2004). Continuous simulation of collection systems can quantify overflow frequency, pump runtime, storage utilization and dewatering characteristics, and other important indicators of wet weather system performance. Continuous simulation is particularly useful when the sequence of storm events and inter-event time are important (ASCE, 1996). Compared to single event simulation using synthetic design storms, continuous simulation with long term historical rainfall can better define storage facility performance and thereby avoid potential over- or under-sizing. However, continuous simulation often requires long run times for complex computer models of large sewer system networks. This chapter presents an innovative approach to reducing the runtime of continuous simulation to size a sanitary sewer storage facility, which was part of the Livingston-James sewer system infiltration and inflow remediation project.

The LJII continuous model was calibrated using synthetic unit hydrograph parameters in SWMM5, using 2007-2008 flow monitoring and rainfall data. Precipitation data for 1949 through 2009 (61 years) from the Port Columbus International Airport gauge were used to generate inflow hydrographs for 1949-2009 using the calibrated model. By compressing inflow hydrographs to achieve effective hydraulic routing through the system, the $61 \mathrm{y}$ simulation model was used to size the storage facility to achieve a design objective of a $10 \mathrm{y}$ level of service.

\subsection{Background}

The LJII project was one of the many I/I projects of the City of Columbus, Ohio. The goals of the project are to identify the locations and causes of sanitary sewerage overflows, to eliminate water in basements (WIBs), and to provide recommendations for system improvements. The recommended alternatives included various combinations of conveyance, I/I reduction, and storage facility. Based on the cost analysis, the storage option has some advantages of cost effectiveness. The study in this chapter was to determine the size of the storage facility to achieve a design objective of a $10 \mathrm{y}$ level of service.

Figure 20.1 shows the LJII study area in Columbus. As part of the project, a SWMM model was developed to assist the system evaluation and support design alternatives. The model includes 2868 junctions and 2915 conduits serving an area of 4669 acres (1 889 ha). The model was first developed with 
SWMM 4.4h, and then converted to SWMM5. The city provided monitoring data from $>10$ flow meters and $>30$ rain gauges for the period 2007-2008. With the long term data, the LJII model was continuously calibrated using the PCSWMM modeling platform (CHI, 2010) with SWMM5 as the computational engine. Precipitation data from Port Columbus international airport is available from 1949 to 2009 . With 61 y of rainfall hyetographs, it is possible to obtain 61 y of inflow hydrographs and route them through the system. However, a major drawback is the computing time. This paper presents a way of reducing the runtime while preserving the $61 \mathrm{y}$ hydrology.

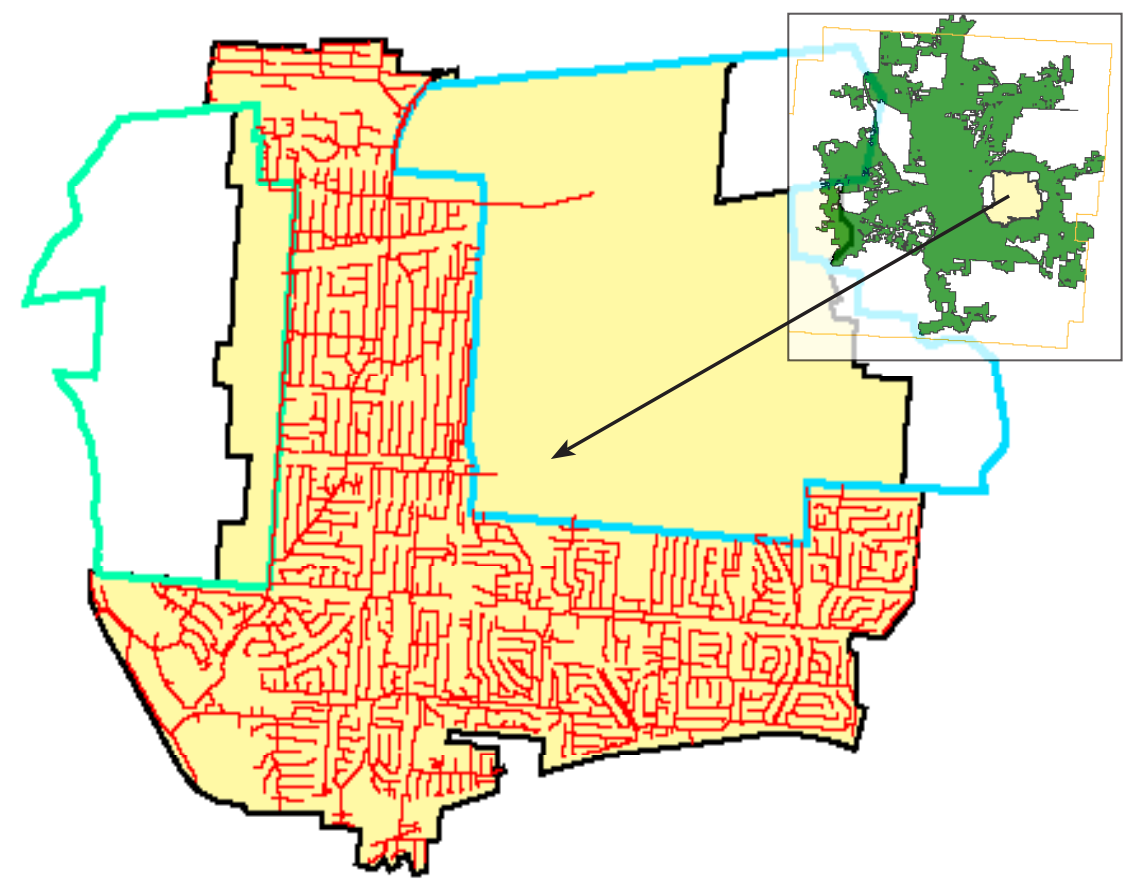

Figure 20.1 LJII study area in Columbus, Ohio.

\subsection{Approach}

First, the LJII model was calibrated for the 2007-2008 period using the flow monitoring and rainfall data. Second, the full hydrologic simulation of a $61 \mathrm{y}$ input stream was performed without hydraulic routing using the calibrated model. Then the inflow hydrographs were compressed to generate a much shorter hydrologic time series to include only periods when storage was potentially active. Finally, full hydraulic routing was achieved by loading the compressed inflow hydrographs and route them through the system. 


\subsubsection{Continuous Calibration of the LJII Model}

The synthetic unit hydrograph (SUH) approach is one the most common empirical approaches to simulating RDII response (USEPA, 2008). SWMM5 is widely used for continuous modeling with the SUH approach (Yeboah and Heineman, 2004). First the original LJII model in SWMM 4.4h was converted to SWMM5 and then quality assurance and control of the model conversion were performed to ensure accurate conversion. In SWMM5, dry weather flow is composed of base wastewater flow and ground water infiltration (GWI). A monthly GWI pattern was developed and input to the model to account for variation of GWI for long term continuous simulation.

SWMM5 uses up to eighteen empirically derived unit hydrograph (UH) parameters to simulate RDII response, including three RTK parameters and three initial abstraction (IA) parameters for short, medium and long terms on a monthly basis (USEPA, 2009). Each of the three terms contains three RTK parameters and three IA parameters. The RTK parameters consist of the fraction of rainfall volume that enters the sewer system $(R)$, the time from the onset of rainfall to the peak of the $\mathrm{UH}(T)$, and the ratio of time to recession to the time to peak of the $\mathrm{UH}(K)$. The IA parameters consist of a maximum possible depth of IA $\left(D_{\max }\right)$, a recovery rate at which stored IA is depleted during dry periods $\left(D_{\text {rec }}\right)$, and an initial depth of stored IA at the start of the simulation $\left(D_{0}\right)$ (USEPA, 2009).

Study in the Columbus area showed significant seasonal variation of RDII response (Cheng et al., 2010). Seasonal RTK and seasonal IA parameters were used for the synthetic unit hydrograph simulation of the RDII response. The dormant season was defined to be December to April and the growth season was defined to be May to November. The continuous model was calibrated for a period of 12 months from June 2007 to May 2008.

The model was calibrated in the following steps to estimate RTK and IA parameters:

1. Calibrate dormant RTK using a multi-peak storm with the longest and highest RDII response in dormant season;

2. Calibrate dormant IA using all storms in the dormant season;

3. Calibrate growth season $R$ (keep TK the same as the dormant season TK) using a multi-peak storm with the longest and highest RDII response in growth; and

4. Calibrate growth season IA by matching other storms in growth season.

The calibrated continuous model was then used for sizing the sanitary sewer system storage facility for a design objective of a $10 \mathrm{y}$ level of service. 


\subsubsection{Development of Compressed Inflow Hydrographs}

The LJII model represents a relatively large pipe network with 2868 junctions and 2915 conduits. To simplify the process, a sub-model covering the upstream of the storage location and downstream pipes affecting the storage was used (see Figure 20.2).

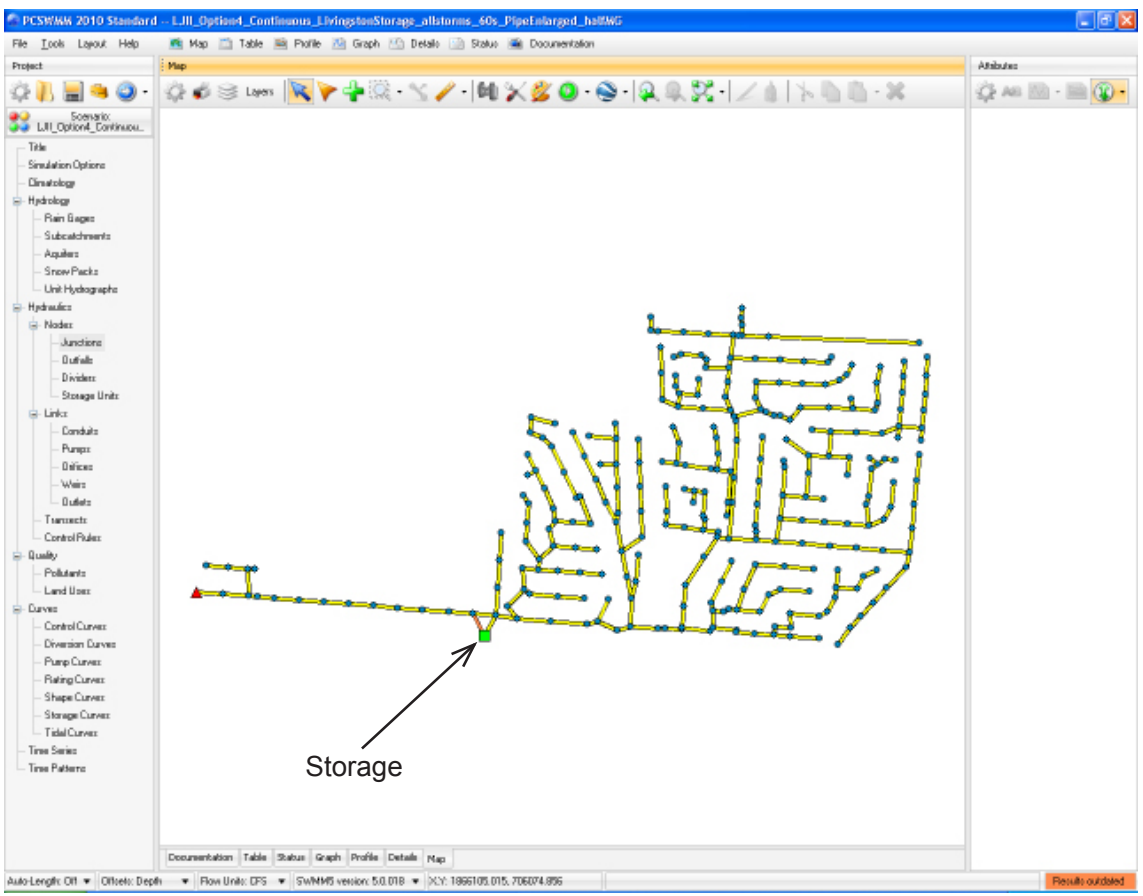

Figure 20.2 Sub-model for Livingston Ave storage sizing.

In total, 281 junctions were upstream of the storage location and 239 of them are inflow loading nodes. The 61 y rainfall for 1949-2009 was loaded into the calibrated continuous model to generate inflow hydrographs for each loading node. The 239 inflow hydrographs for the loading nodes upstream of the storage were summed up to obtain the un-routed total inflow hydrograph at the storage node as shown in Figure 20.3. The $61 \mathrm{y}$ total inflow hydrograph at the Livingston Ave storage was then compressed by using the downstream pipe capacity as a threshold to identify any storm that would potentially activate storage utilization. Full flow capacity at the pipe downstream of the Livingston Ave storage was as $10.9 \mathrm{cfs}(308.7 \mathrm{~L} / \mathrm{s})$. 


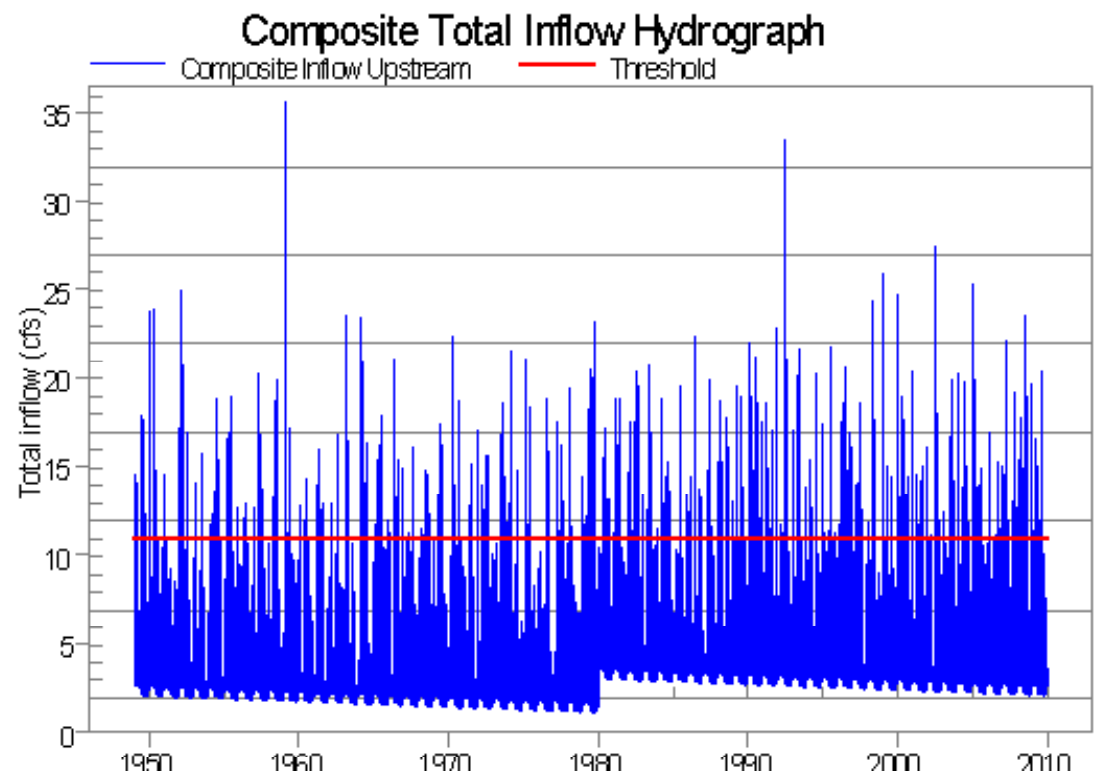

Figure 20.3 Total Inflow hydrograph at Livingston storage.

Composite Total Inflow Hydrograph

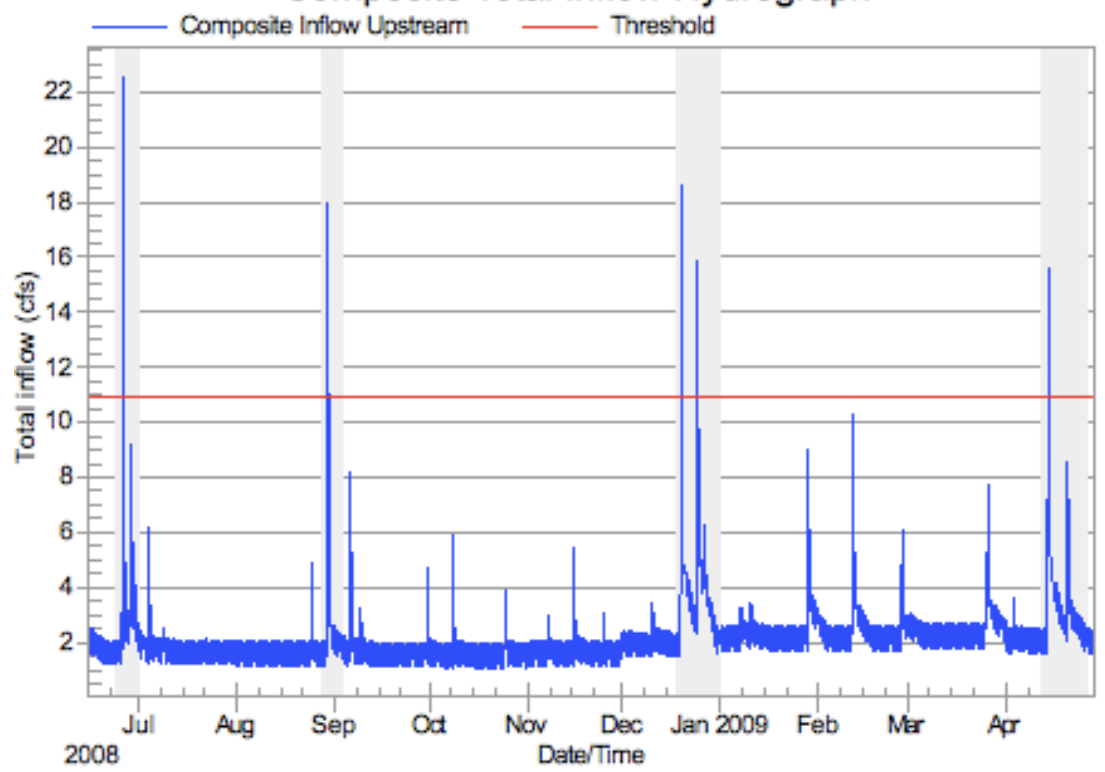

Figure 20.4 Compression of total inflow hydrograph. 


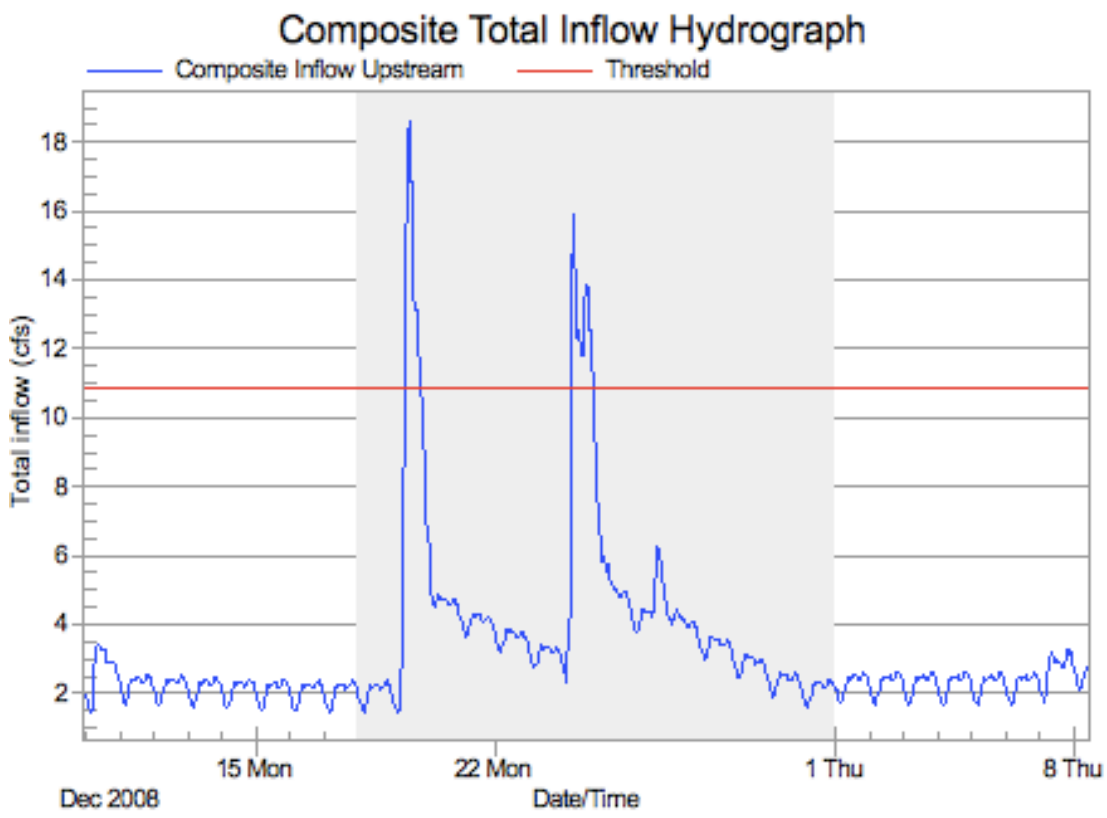

Figure 20.5 Example of a selected storm period.
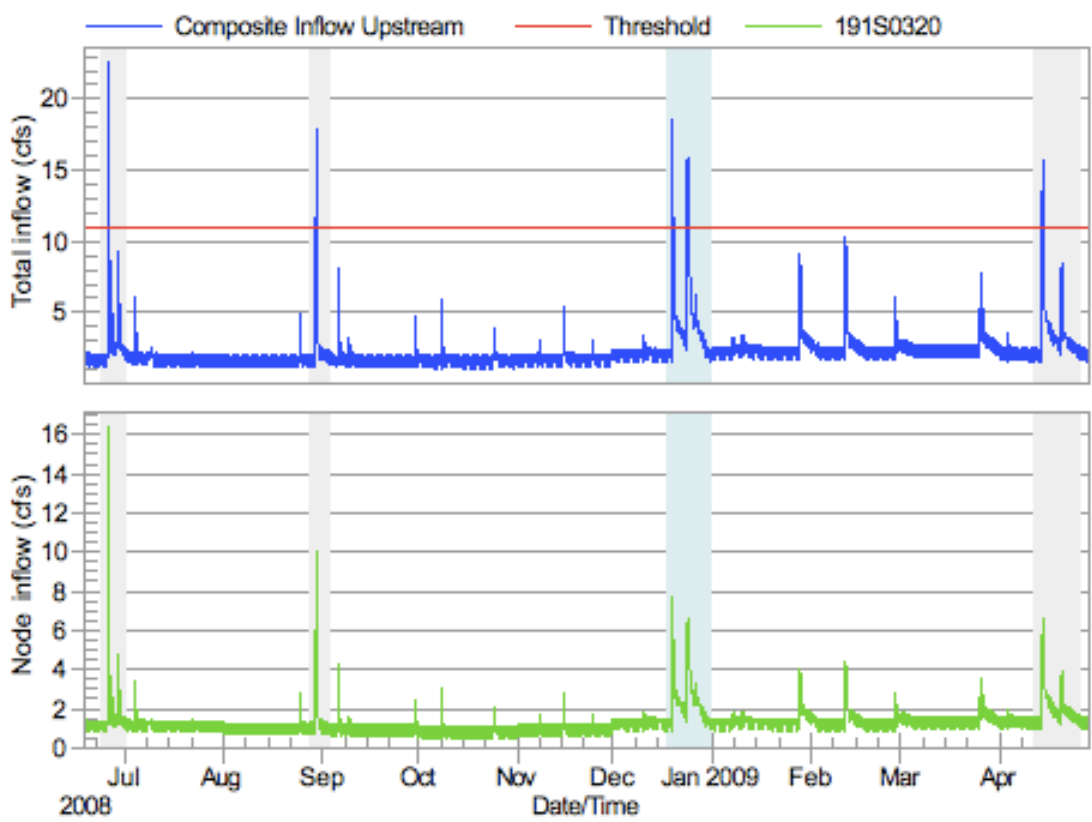

Figure 20.6 Compression of an inflow hydrograph using selected storm time periods of the compressed total inflow hydrograph. 
The unrouted total inflow hydrograph upstream of the storage was compared with the downstream pipe capacity as shown in Figure 20.4 above. Any storm with an inflow value at a time step higher than the threshold was included in the compressed inflow hydrographs. As shown in Figure 20.5 above, each extracted hydrograph includes a complete RDII response starting and ending at dry weather flow conditions with an extra dry day added before each storm hydrograph to allow sufficient time for emptying the storage facility. After this step, a compressed time period was obtained to represent the $61 \mathrm{y}$ hydrology.

The same compressed time period was used to compress the inflow hydrographs at each loading node as shown in Figure 20.6 above. Then each loading node in the sub-model had a compressed inflow hydrograph for hydraulic routing to size the Livingston Ave storage.

\subsubsection{Analysis of Storage Performance}

Storage and pumps were set up in the model, as shown in Figure 20.7, for hydraulic routing to determine the size of sanitary sewer system storage facility for a design objective of a $10 \mathrm{y}$ level of service. The maximum of storage elevation was set up as $8 \mathrm{ft}(2.44 \mathrm{~m})$ below the lowest ground elevation upstream of the storage location. In this case, no potential basement flooding would occur when the storage is filled. The pumping rules for Pump into Storage were set up to allow flow into storage when flow rate in the upstream pipe reached capacity. The Livingston Ave pump station starts dewatering when the downstream pipe flow rate becomes less than full pipe capacity.

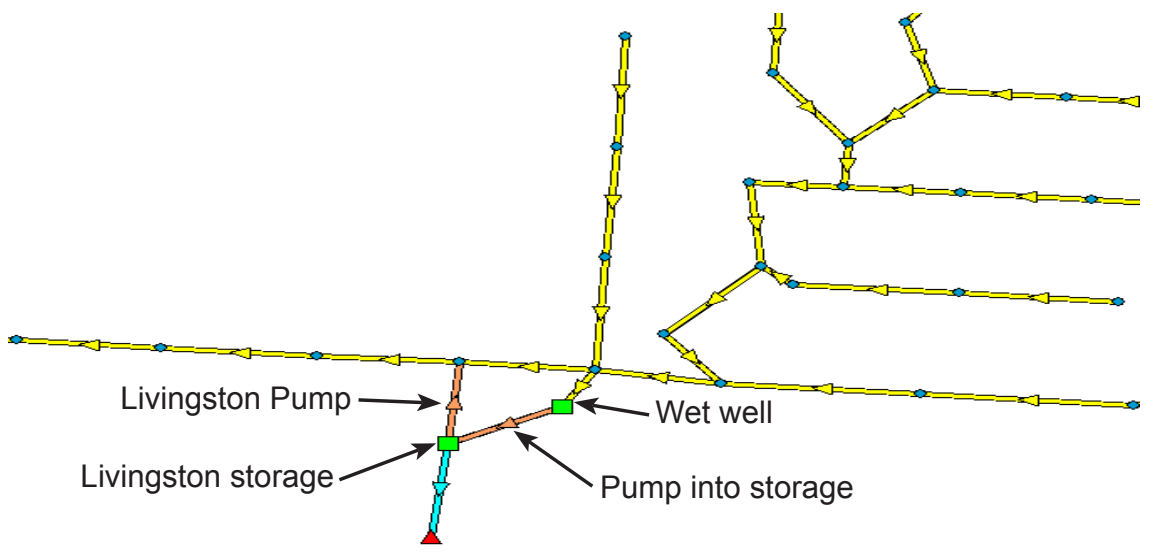

Figure 20.7 Livingston storage setting in SWMM 5 model using the PC-SWMM platform. 
The $61 \mathrm{y}$ inflow hydrographs were compressed into a 7.8 y period including a total of 272 selected storm events to potentially activate the storage. An artificial continuous 7.8 y period starting from 20120101 was assigned to the compressed inflow hydrographs. Figure 20.8 shows how the selected storm periods were connected using artificial time steps to become a continuous inflow time series for continuous hydraulic routing. The $7.8 \mathrm{y}$ inflow hydrographs were routed through the system to determine the size of storage which can be filled only six times in 61 years ( $10 \mathrm{y}$ level of service) based upon the actual rainfall data.

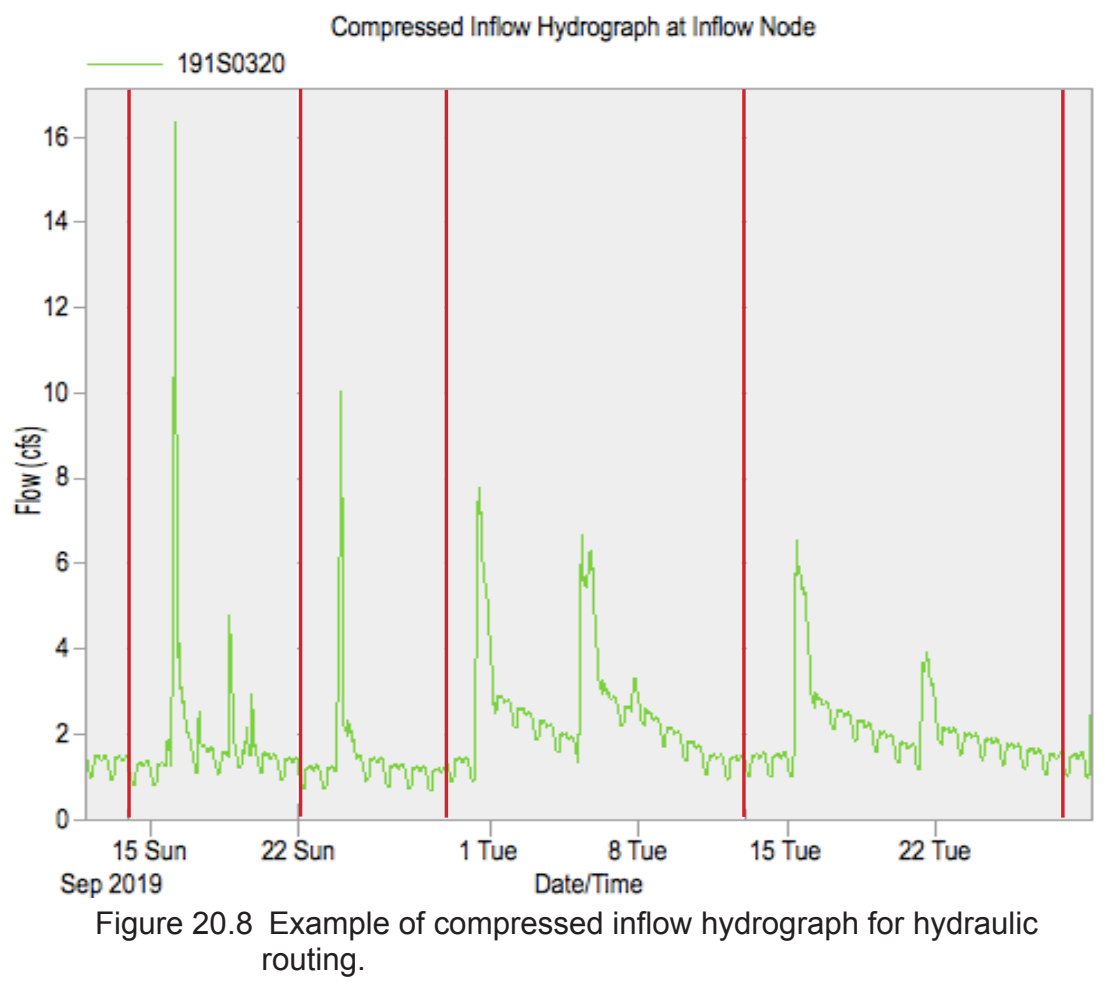

\subsection{Results and Discussion}

Hydraulic routing of the $7.8 \mathrm{y}$ of compressed inflow hydrographs showed a total of 48 times of storage activations during $61 \mathrm{y}$ period 1949-2009. The size of the Livingston Ave storage for a $10 \mathrm{y}$ level of service was identified to be $0.75 \mathrm{MG}(2.84 \mathrm{ML})$ to achieve six occurrences of full utilization in $61 \mathrm{y}$. Figure 20.9 showed the six times of full usage of the storage during the $7.8 \mathrm{y}$ 
artificial time period compressed from the 61 years. The top ten storms in terms of maximum volume in the storage are shown in Table 20.1.
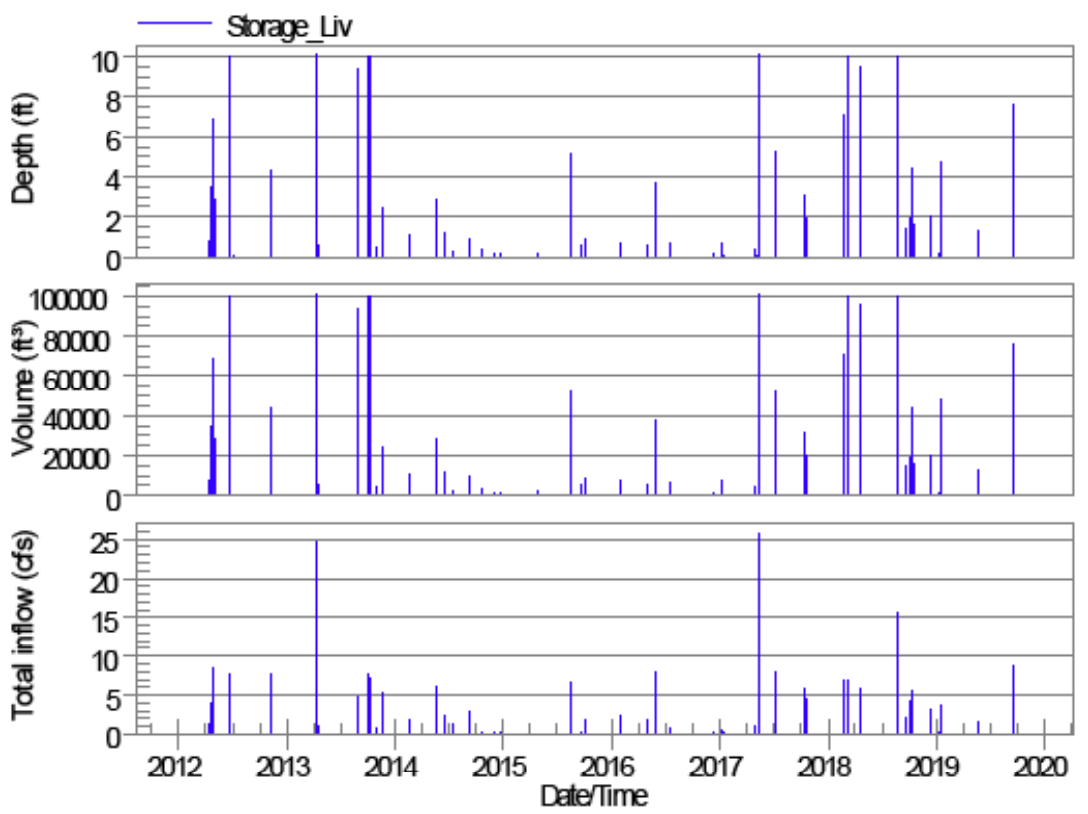

Figure 20.9 Inflow, depth and volume in the Livingston Ave storage.

Table 20.1 Top ten storms to activate Livingston Ave storage 19492009.

\begin{tabular}{cccccc}
\hline No. & $\begin{array}{c}\text { Maximum } \\
\text { Depth (ft) }\end{array}$ & $\begin{array}{c}\text { Maximum } \\
\text { Volume (MG) }\end{array}$ & $\begin{array}{c}\text { Simulation Storm Start } \\
\text { Date and Time }\end{array}$ & $\begin{array}{c}\text { Actual Storm Start } \\
\text { Date and Time }\end{array}$ & $\begin{array}{c}\text { Storage } \\
\text { Activated } \\
\text { Time (hr) }\end{array}$ \\
\hline 1 & 10.09 & 0.75 & $05 / 10 / 201704: 00$ & $07 / 13 / 199204: 00$ & 22 \\
2 & 10.08 & 0.75 & $04 / 06 / 201308: 00$ & $01 / 21 / 195908: 00$ & 38 \\
3 & 10.04 & 0.75 & $10 / 01 / 201320: 00$ & $03 / 04 / 196420: 00$ & 79 \\
4 & 10.04 & 0.75 & $06 / 20 / 201214: 00$ & $01 / 26 / 195214: 00$ & 32 \\
5 & 10.02 & 0.75 & $03 / 04 / 201822: 00$ & $12 / 21 / 199822: 00$ & 25 \\
6 & 10.02 & 0.75 & $08 / 23 / 201816: 00$ & $07 / 23 / 200216: 00$ & 21 \\
7 & 9.52 & 0.71 & $04 / 15 / 201823: 00$ & $01 / 03 / 200023: 00$ & 26 \\
8 & 9.39 & 0.70 & $08 / 25 / 201318: 00$ & $03 / 04 / 196318: 00$ & 25 \\
9 & 7.61 & 0.57 & $09 / 16 / 201903: 00$ & $06 / 26 / 200803: 00$ & 17 \\
10 & 7.13 & 0.53 & $02 / 18 / 201807: 00$ & $04 / 16 / 199807: 00$ & 18 \\
\hline
\end{tabular}

The approach used in this study showed that the hydrologic response to the full historical precipitation record was simulated to assure proper 
characterization of the inter-event hydrologic responses. Full hydraulic routing of the storage events was also simulated to assure the proper characterization of the storage responses. The approach achieved full hydraulic routing in an effective way by omitted hydraulic routing during those periods for which there is no storage inflow or outflow, which is unnecessary for the proper characterization of storage.

\subsection{Conclusion}

Using long term continuous simulation to size storage facilities can be practical, even for large complex sewer models, but may require special techniques to reduce the size of the inflow hydrographs that are routed through the pipe network. An advantage of this continuous simulation approach using the $61 \mathrm{y}$ inflow hydrographs is that it enables the simulation of RDII without losing the influences from previous storms and moisture conditions, while maintaining reasonable runtimes to support generating and evaluating different design criteria for different levels of service.

\section{References}

ASCE (1996). Hydrology Handbook, Second edition, Chapter 9: Urban Hydrology.

Cheng, F., B.J. Sherman, G. Barden, H. Kelly, T. Fallara and E. Burgess. 2010. "Comparison of RDII Unit Hydrograph Approaches for Continuous Simulation using SWMM 5." Journal of Water Management Modeling R241-12. doi: 10.14796/JWMM.R241-12.

CHI (2010). PCSWMM 2010 user documentation. Computational Hydraulics Int., Guelph, Ontario, Canada

USEPA (2008). Review of Sewer Design Criteria and RDII prediction methods.

USEPA (2009). Storm Water Management Model User's Manual Version 5.0.

Yeboah, M. and Heineman, M. (2004). Selection of a Representative Long-Term Period for Continuous Model Simulation, ASCE World Water Congress, p. 1-13. 
